\title{
Theoretical Ecology: Continued growth and success
}

\author{
Alan Hastings \\ Published online: 23 January 2010 \\ (C) The Author(s) 2010. This article is published with open access at Springerlink.com
}

Our journal has finished another very successful year. The journal continues to attract top quality articles in a variety of areas in theoretical ecology. Among the highlights are that the journal is now covered by ISI, with all articles from the first issue of the first volume indexed in Web of Science. This coverage in such a short time since the inception of the journal is a real honor. Articles from the journal have been highlighted in the Faculty of 1000 .

Quantitative measures also point to continued success and growth. Submissions have grown from 39 in calendar year 2007 to 55 in 2008 to 71 in 2009. Submissions in the last year represent theoretical ecology from around the world: 20 from the United States, 20 from Europe excluding the United Kingdom, 11 from Canada, 10 from the United Kingdom, and 10 from other areas. We also have been both selective in the choices of which manuscripts to accept and have been able to reach a decision quickly. The mean time to the first decision in the last year has been 52 days, due in part to the diligence of our editors and even more to the responsibility taken on by our reviewers. The care and responsiveness of the community in reviewing manuscripts for Theoretical Ecology has been especially heartening.

Reflecting the state of ecology, articles appearing in the journal during this past year are difficult to classify in a single subfield, though several areas have been the focus of a number of articles. Evolutionary ecology has been very well represented, as have been studies at the ecosystem level. Many articles have focused on areas that will be important for applications and management: understanding species invasions, and bioeconomic approaches. Reflecting current interest, several articles have considered the detection and implications of regime shifts. The journal continues to attract articles that mirror the breadth of current work in theoretical ecology, which is rapidly expanding beyond the classic approaches in population biology that date back to the early part of the twentieth century.

The journal will continue to welcome contributions in all areas of theoretical ecology, ranging across all subfields of ecology, and ranging from non-mathematical approaches to computational approaches to those contributions which rely heavily on careful mathematical arguments. As stated in the aims and scope of the journal, the papers we seek "use theoretical approaches to answer questions of ecological interest and appeal to and are readable by a broad audience of ecologists." During the next year we will look for contributions of review and synthesis papers. If you have any ideas for improvement or any other suggestions, please do not hesitate to contact me.

Open Access This article is distributed under the terms of the Creative Commons Attribution Noncommercial License which permits any noncommercial use, distribution, and reproduction in any medium, provided the original author(s) and source are credited.

A. Hastings $(\bowtie)$

Department of Environmental Science and Policy,

University of California, Davis,

Davis, CA 95616, USA

e-mail: amhastings@ucdavis.edu 